\title{
Assessment and modeling of sewer network development utilizing Arc GIS and SewerGEMS in Kabul city of Afghanistan
}

\author{
Ali Reza Noori* and S.K.Singh** \\ * Department of Environmental Engineering, Delhi Technological University, Delhi, India, \& Department of Water Supply and Environmental \\ Engineering, Kabul Polytechnic University, Kabul, Afghanistan \\ ** Department of Civil and Environmental Engineering, Delhi Technological University, Delhi, India \\ ** Corresponding Author : sksinghdce@gmail.com
}

\begin{abstract}
The absence of a wastewater collection, management, and disposal scheme is one of Kabul's most serious environmental issues. This has resulted in both health and ecological problems. This research used Arc GIS and SewerGEMS tools to assess the viability of a decentralized sewerage collection model in the research area. The research area was chosen as the city's 5th district. Land-use and land-cover, Digital Elevation Model (DEM), and Satellite data were used to construct the network's geometry in the Arc map environment. SewerGEMS software was used to perform hydraulic simulation and modeling. The variables were regulated based on the results of the study using conventional wastewater topology guidelines. Based on the outputs of hydraulic analysis, it is concluded that the decentralized wastewater collection system would be the best option for the area. It can be deduced from hydraulic design findings that the hydraulic model was successfully developed and built. The methodology can be applied for the development of future wastewater master plans of the city.
\end{abstract}

Keywords: Hydraulic analysis; Sewer networks; Kabul city; Wastewater collection network; Arc GIS; sewerGEMS.

\section{INTRODUCTION}

Wastewater collection, treatment, and proper disposal are the main sanitary requirements of every civilization. Methods for treating, preserving, collecting, and disposing of wastewater can pose risks to the environment and public health (Chawla \& Singh, 2014). For organizations and management of urban water and sanitation systems, the effective approach for various areas of the city is the right and timely selection of alternatives that should be specified in terms of physical characteristics, financial, economic, and social acceptance results. The absence of a wastewater collection, management, and disposal scheme is one of Kabul's most serious environmental issues. This has resulted in both environmental and health issues. Nowadays, blackwater is disposed of using sewage and septic tanks, semi-insulated wells, traditional (dry) toilets, and absorption pits (wells). The greywater is also disposing of by utilizing the same methods but is mainly discharging into the open environment. Kabul Municipality has implemented a small-scale biological wastewater treatment scheme and claimed that groundwater would be unusable in the coming years unless urgent and comprehensive steps are taken to deter groundwater contamination in Kabul (Shafaqna, 2019).

Groundwater becomes Kabul's main reliable and accessible source of drinking water (Zaryab et al., 2017). Fecal coliforms have poisoned drinking water and several groundwater sources (Afzali, 2017). Kabul's groundwater is in 
bad quality, according to reports (Afzali, 2017; Brati et al., 2019; Frahmand, 2011; Gesim \& Okazaki, 2018; Hayat \& Baba, 2017; Houben \& Tünnermeier, 2005; Noori \& Nasimi, 2019; Rhimi \& Murakmi, 2017). The emissions have a negative impact on the capital's environment. There are no statistics available on the disease or its causes. According to a study on the BBC website on August 10, 2017, (Ali, 2017), tainted water is the primary source of pathogens in Kabul. According to Antani hospital physicians, polluted water supply is the primary factor of pandemics in more than $70 \%$ of patient populations enrolled at the hospital.

According to the existing literature, generally, it can be argued that the city currently lacks a system for collecting and disposing of sanitary wastewater. Just $1 \%$ of the town's population is connected to the municipal sewage network, which is also partially active. Based on the current statistics, of the total greywater of residential area $83 \%$ and commercial areas, $59 \%$ are discharging to open environment. Also, $49 \%$ of the total blackwater in residential areas and $81 \%$ in commercial areas are disposed of by holding tanks (Consortium for DEWATS Dissemination Society, 2017; Paiman \& Noori, 2019). In general, it can be said that the collection and disposal of wastewater by mentioned methods in the city with a population of nearly five million people pose a serious health risk to the lives of all citizens. Furthermore, this requires urgent and immediate action to measure a regular and comprehensive management system for wastewater collection, treatment, and disposal. On the other hand, the utilization of treated wastewater can cause a clean environment and help water resources, especially in arid and semi-arid areas (Aleisa \& Alshayji, 2019).

The integrated use of geostatistical approaches, remote sensing, and spatial analysis offers valuable knowledge for detecting, simulating, and discovering environmental components (Kanakiya et al., 2015). The aim of this article is to use Arc GIS and SewerGEMS tools to conduct a preliminary conceptual design for wastewater collection systems in the study area. A land-use and land-cover (LULC) mapping and a Digital Elevation Model (DEM) and aerial photographs are being used for geometric modeling in this analysis. Bentley's SewerGEMS Version 8i was used to perform hydraulic evaluation and network construction. Moreover, variables are monitored based on the study findings and generic sewerage network configuration guidelines.

\section{STUDY AREA}

More than half of the global population currently lives in cities, indicating rapid urbanization is a global phenomenon (Bhave \& Rahate, 2018; Bu Qammaz et al., 2020). Kabul, Afghanistan's capital, is situated in the country's central east. The city located geographically in $34^{\circ} 39^{\prime} 20^{\prime \prime} \mathrm{N}$ to $34^{\circ} 17^{\prime} 40^{\prime \prime} \mathrm{N}$ latitude and $69^{\circ} 31^{\prime} 40^{\prime \prime} \mathrm{E}$ to $69^{\circ} 52^{\prime} 40^{\prime \prime} \mathrm{E}$ longitude. The annual average precipitation in the basin measured at around $330 \mathrm{~mm}$ per year (Source: Afghanistan meteorological department, data recorded 2008-2018). The temperature ranges with a monthly mean of a maximum of $32^{\circ} \mathrm{C}$ in July and a minimum of $-7^{\circ} \mathrm{C}$ in January (Zaryab et al., 2017). It has a population of 4.3 million people (CIA, 2020; NSIA, 2020) and is the country's largest financial center.
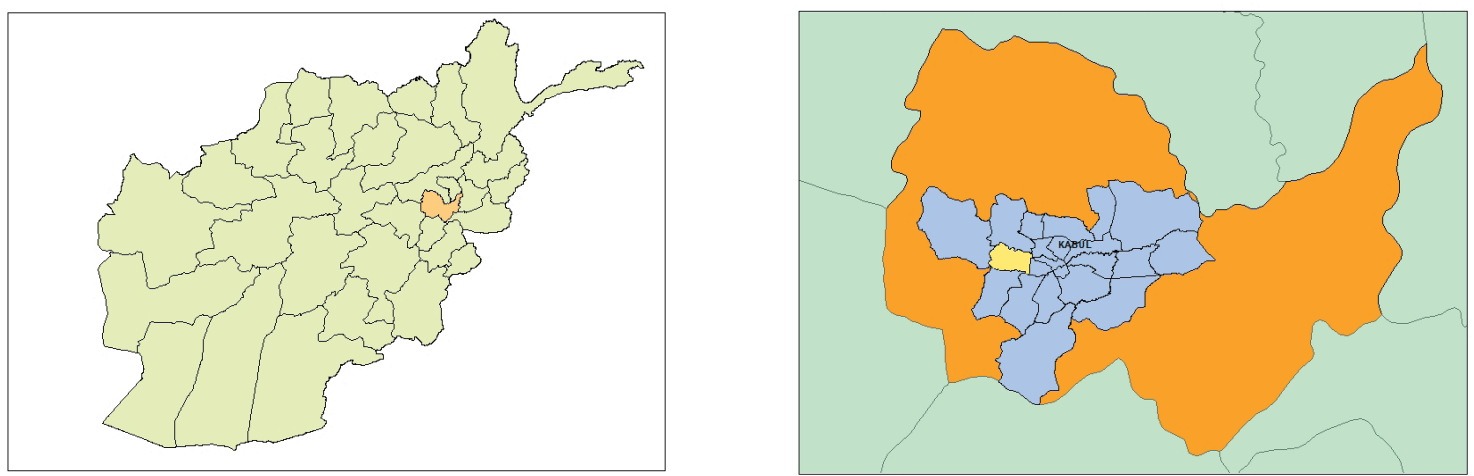


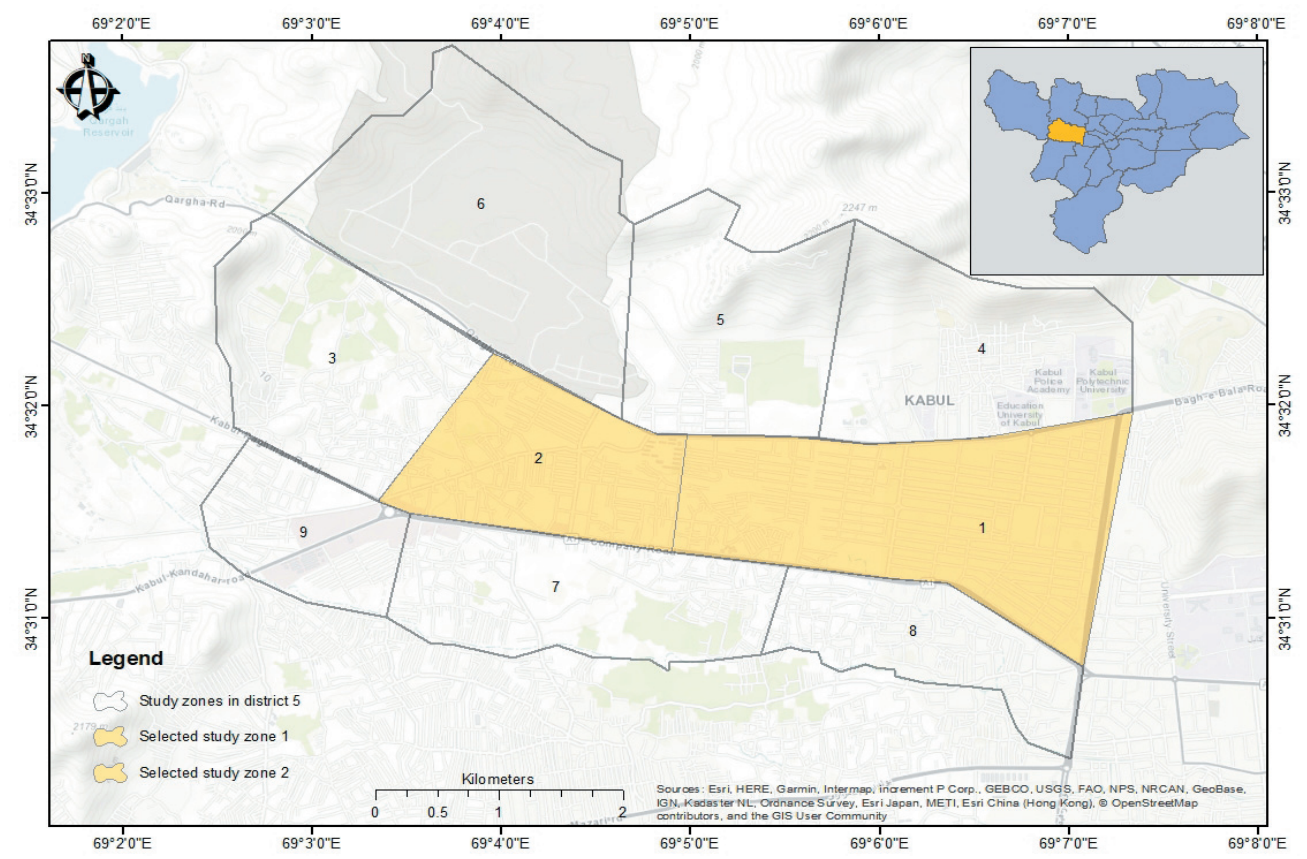

Figure 1. Location map of the study area

There are 22 separate city districts in the area. The planned research area is district five, situated in the western neighborhoods (Figure 1). This area is a built-up area of the capital, with an approximate total of 86000 people, as per Kabul municipal statistics. It has a total area of approximately $28 \mathrm{sq} . \mathrm{km}$ and a circumference of approximately $30 \mathrm{~km}$. This field was chosen for the research because it encompasses both developed and unplanned zones. The planned area has covered only about $18 \%$ of it. The remaining $82 \%$ has developed in an unplanned manner. The study and modeling of the whole region are beyond the scope of this study. Consequently, the research area was already split into nine spatial variabilities, with the model established for just two of them (Figure 1). Both zones occupy a combined area of around nine sq. km, covering the developed region and the other an unplanned location. Topographic trends and projected planning were also taken into account when deciding on research zones. It would be easy to combine the concept to the current areas' primary sewer lines if it is developed in the future.

\section{MATERIALS AND METHODS}

The GIS technology greatly simplifies different geospatial scales and can reduce the expense and time of site observations, which is essential for environmental preservation (Kanakiya et al., 2015; Kumar et al., 2015). The sanitary sewer scheme for Kabul's 5th district was modeled in this study. The methodological flowchart is presented in (Figure 2). First, using Arc GIS software, the necessary details were calculated, such as the lengths of the sewage pipes, the surface, and ground level at the manhole positions. After which, in the target geographic region, similar details, including topography, statistical data such as population growth, water use, and sewage generation, were scheduled.

To create a geometric model, the availability of LULC is necessary for the study area. The LULC map created by Afghanistan's ministry of earth and urban development in 2016 was used. Built-up zones, farming, industrial, and administrative regions are included in the LULC. The relative position of motorways in the area has been depicted in LULC (Figure 3a). The number of homes in the area was estimated by the LULC using aerial imagery from the Kabul district. The households are used to estimate the populace and mass flow for hydraulic simulation of the network. 


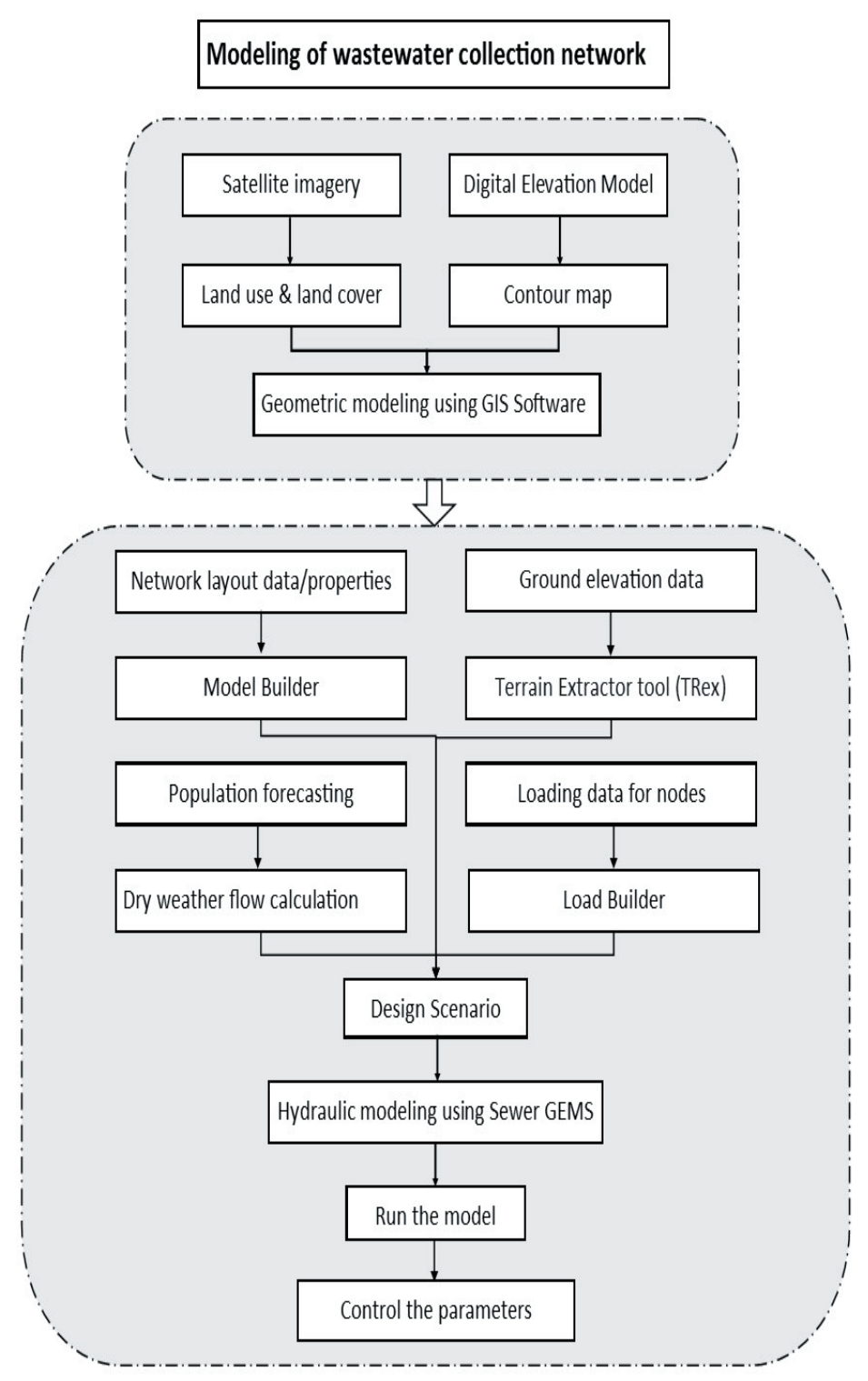

Figure 2. Methodology flowchart showing the modeling of a sewerage network.

For proper network navigation, the contour lines and topography of the region are also used. In practice, this is accomplished by a survey, which takes a significant amount of time and money. DEM, on the other hand, is utilized for analysis and the development of primary schema. DEM is a kind of open-source data that comes in a variety of resolutions. A 30-meter resolution was used in this study.

Bentley's SewerGEMS platform for designing hygiene and hybrid sewerage is one of the company's most popular products. The necessary details and schematic layout of the system were developed using Arc GIS 10.6 in this study. The volume of discharge was calculated based on per person wastewater generation in various locations and the necessary information inserted in SewerGEMS to hydraulically analysis the model. The network's architecture was developed using the research area's LULC and topographical map (Figure 3b). The network's architecture depicts the model's first figures. Based on the network's layout, the manholes' relative positions, and the critical network routes suggested. 


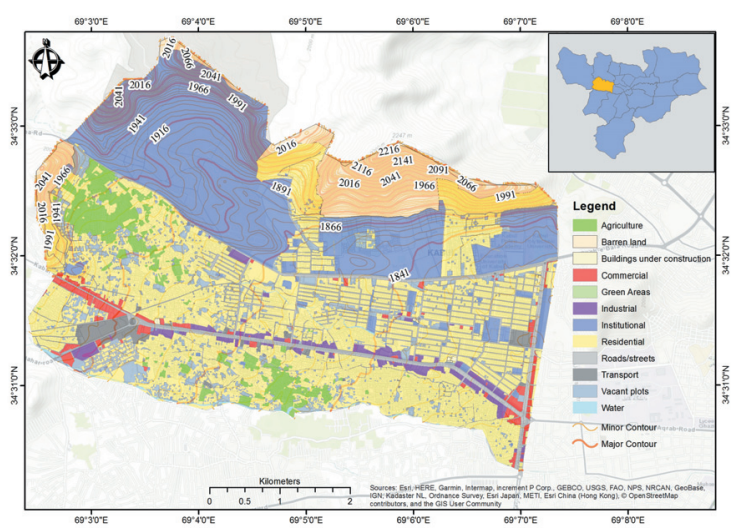

a) LULC of the study area

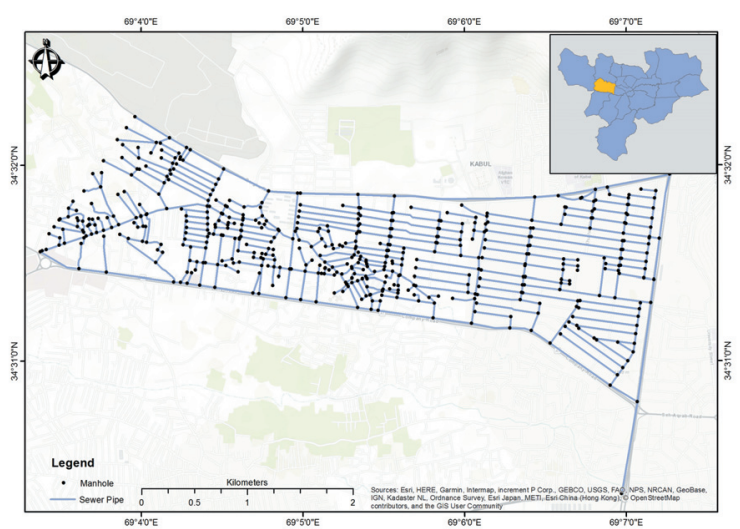

b) Geometric model of the sewer network

Figure 3. LULC and geometric of the model

ModelBuilder is a tool available in the Bentley SewerGEMS product that allows the creation and updates of a model from a source file (Akshaya \& Jesse, 2020). The shapefiles created in the Arc GIS environment were utilized for modeling using the ModelBuilder technique in SewerGEMS. The Terrain Extractor (TRex) tool will automatically allocate elevation to any node based on the nearest elevation of the .dxf contour, shapefile, LandXML file, or location elevations (Dan \& Jesse, 2020b). This method is applied in the model for ground elevation in manholes locations. In order to assign the loads to the hydraulic model, the LoadBuilder method is used in the SewerGEMS environment. In this model, proportional distribution by area (Dan \& Jesse, 2020a) is applied to assign loads on the network.

\section{RESULT AND DISCUSSION}

\section{Population Density and Discharge Estimation}

Kabul has a population of 4.3 million people and a land area of 1023 sq. km. Its density of population is 4500 people per sq. $\mathrm{km}$. The total space occupied by both study zones in the 5 th district is $8.834 \mathrm{sq} . \mathrm{km}$. As a result, the population density will be used to estimate the population of the coverage region, which is estimated to be around 40,000 inhabitants. From the other side, the research area is primarily made up of middle and high apartment blocks, which would directly affect population growth. As a result, the current population in the research area is given an extra multiplier (security factor $=1.8$ ) to enhance continued stability. As a result, the research area's population is expected to be 72,000 residents. Kabul is among the fastest-growing cities in the world. Calculating the population growth is one of the principles and requirements for hydraulic analysis of the model. The geometric approach is a well-known and commonly used method for population estimation.

$$
P_{n}=P_{0}(1+r)^{n}
$$

Where; Pn- Population in the desired year, $\mathrm{P}_{0}-$ the current population, $\mathrm{r}-$ increasing rate, $\mathrm{n}$ - number of years of the design period.

The life of sanitation projects is typically estimated to be about 30 years based on design specifications. The population is expected to rise at a rate of $(2.5 \%)$ each year. By considering these factors, the population for the next 30 years was estimated as follows. 


$$
\mathrm{P}_{30}=72000\left(1+\frac{2.5}{100}\right)^{30}=151025 \text { capita }
$$

The volume of sewage flowing into the system is equal to the volume of water used in residence. Just the volume of sewage flow in suburban areas without rainwater is determined since this model is not considered a hybrid. Based on the existing condition, water demand in cities of the country is taken equal to 100 liters per capita per day (Seddeqi, 2017)Afghanistan","title":"Water Supply Engineering","type":"book"\},"uris":["http://www.mendeley. com/documents/?uuid=ed11a0e5-d019-414a-8729-a6a8e53337f1"]\}],"mendeley": ‘“formattedCitation":"(Seddeqi,

2017. Therefore, the volume of sewage generation is also counted equal to 100 liters per capita per day. By using water demand and population density, the total volume of flow can be determined as follow:

$$
\mathrm{Q}_{\mathrm{avg}}=151025 \times 100=\frac{15102500 \mathrm{lit}}{\mathrm{d}}=15102 \mathrm{~m}^{3} / \mathrm{d}
$$

The determined volume of sewer flow from households (Dry Weather Flow = DWF) is equal to $15102 \mathrm{~m}^{3} /$ day. According to the design requirements for wastewater collection systems, a safety factor (s.f. $=2$ ) must be added for the efficiency operation of the model. Groundwater penetration, stormwater flows, frequent variation all contribute to this Safety aspect. The following formula is used to calculate the overall maximum outflow:

$$
\mathrm{Q}_{\max }=15102 \times 2=30204 \mathrm{~m}^{3} / \text { day }
$$

\section{HYDRAULIC MODELING AND ANALYSIS}

The main objective of a hydraulic analysis of the network is to examine the architectural model that was previously created in the Arc map environment. In many forms of sewer network analysis, hydraulic models are the most effective methodology (Zhang et al., 2018)Norway. The purpose of the control is to use the free space of the pipes to reduce overflow at the wastewater treatment plant (WWTP. Specifically, the goals of hydraulic design are to determine the required diameter of sewer pipes, calculate and control the slope and control the flow velocity in sewer pipes. Since velocity is a critical component in fluid dynamics, it has definite limits according to design criteria. Also, the sewer pipes are designed in incomplete filled, so the ratio of fullness and emptiness of the pipelines must be specified in hydraulic calculations.

The load on the model was applied using the "area load" technique in this analysis. The spread of discharge in the pipelines has also been achieved using "Equal Flow Distribution." The flow of all pipelines is distributed proportionally based on the area occupied per pipeline. Since some pipelines may have more loads and others may have fewer, such a circumstance will not manifest in practice. This approach is called the most suitable loading framework since this model was developed to investigate the viability of modeling.

The following design scenario was considered for the hydraulic design: a) The type of pipe material selected is, Polyvinyl chloride (PVC). b) Pipeline's diameter range is between 15 to $60 \mathrm{~cm}$. c) The high and low-velocity limits are assumed 60-300 cm/sec. d) Depth of burial of pipelines according to frost depth considered within 90 to $400 \mathrm{~cm}$. e) The slope for piping was set among 0.005 and 0.1 percent. f) All pipelines are considered half-full (50\%) flow. The created model has been validated to evaluate the input data and design settings scenario. while the validation process was completed, the model was run to perform hydraulic analysis. The software measures and analysis numerical and analytical variables. 


\section{Presenting and Evaluating the Results}

Different techniques are available to display the analysis results in SewerGEMS software. The "design report" illustrates a summarized overview of the analyzed network. The information such as specifications of the designer, title of the project, name of the organization, date of analysis, and design. It also gives brief information about the applied scenario in the creation of the model. It represents the exact amount of each element utilized in the network. In this study, a total number of 521 pipelines and manholes adding one outfall are being used. Furthermore, it gives the lengths and diameters of all diameter ranges of the pipelines used in the model (Figure 5). A total length of $92602.4 \mathrm{~m}$ pipelines were used in this modeling.

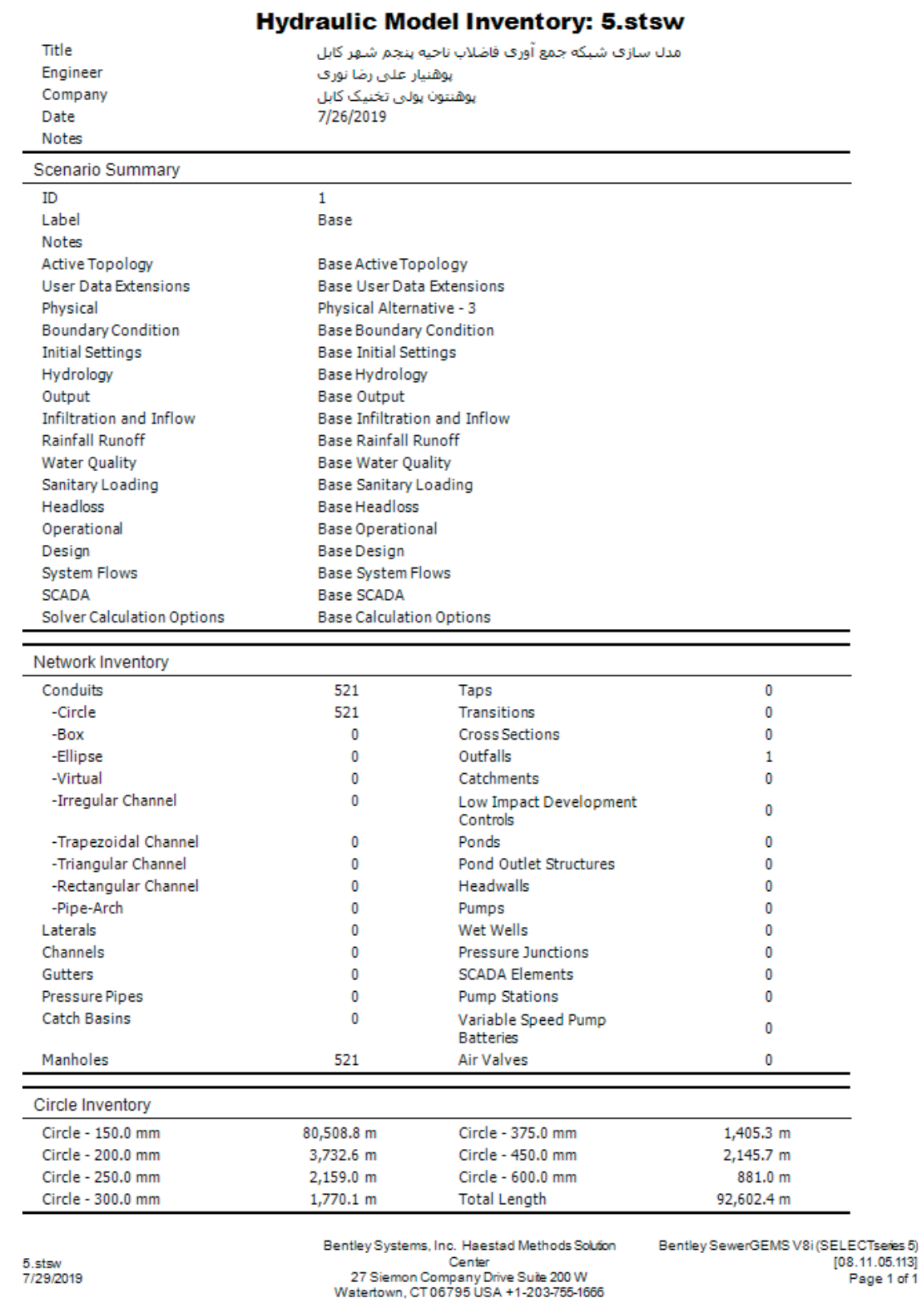

Figure 4. Summary of hydraulic design 
It is possible to display separate tables in the software and observe the design details to see more information about manholes and pipelines. The materials utilized in the design of the pipelines, the length of each branch, and all the required figures can be displayed in the program report. Another method that can be used to see the results is diagram illustration. The graph representation in terms of time in various model components can be used to explain variation in the component in the context of a map. The adjustment in "hydraulic gradient" in a manhole over the course of 24 hrs is expressed in (Figure 5). If the extended duration approach is utilized in the design case, this technique yields a concrete outcome.

The sewer network profile is a crucial component that should be displayed. The profile of all pipelines is essential for the implementation of sanitation projects. The critical path, also known as the farthest path, can be seen in (Appendix A\&B). The profile can include surface level, manhole depth, invert altitude, pipeline slope, width, and other required parameters.

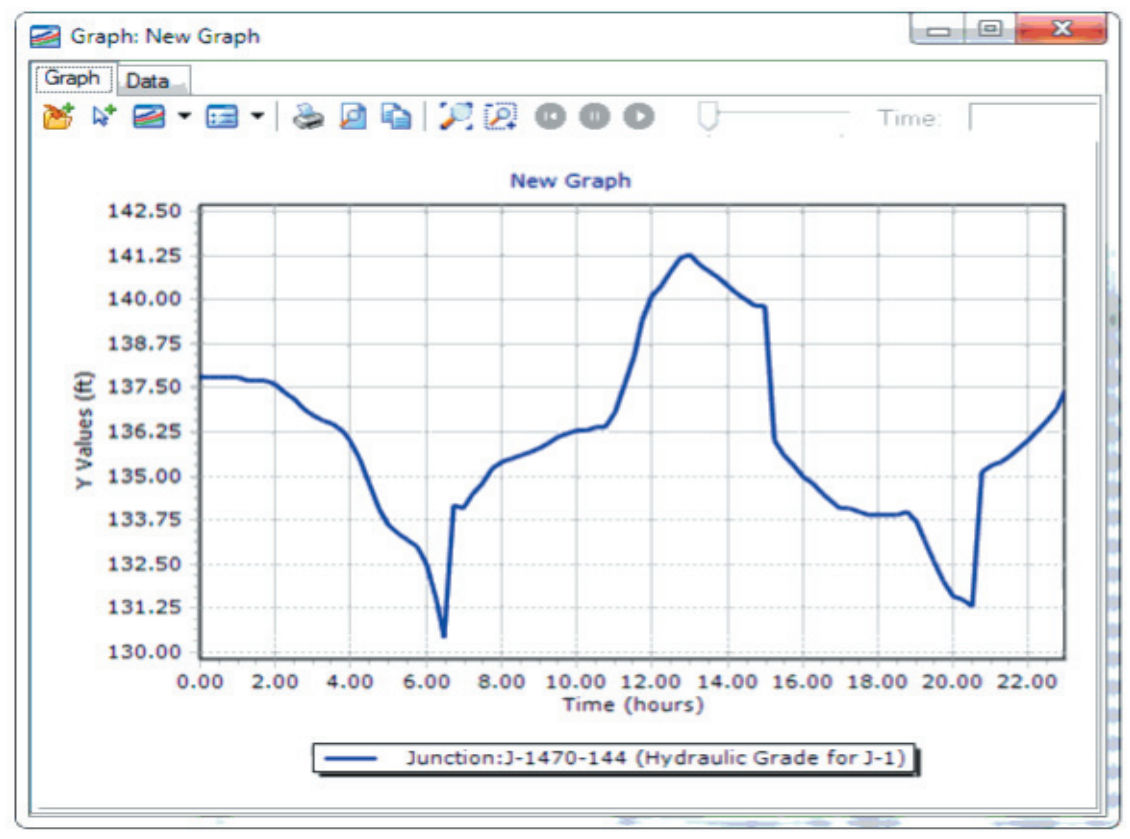

Figure 5. Hydraulic Gradient for J-1

\section{Control of Parameters}

Some modules may be used as control parameters to consider the correctness and precision of the design and hydraulic analysis. For example, speed of flow (velocity) is a component that can be examined. Based on the design requirements, sewage network velocity limits vary from 30 to $500 \mathrm{~cm} / \mathrm{sec}$ with an ideal range of 60 to $180 \mathrm{~cm} / \mathrm{sec}$. As a result, it can be said that in the wastewater collection modeling, the velocity should be within the applicable limits, if not the optimal height. The velocity of flow in all pipelines reported within the scope of 30 to $487 \mathrm{~cm} /$ sec, as seen in (Appendix C). Like pipeline diameters added as usual from the software library, other variables can be monitored, checked, and measured according to the flow volume. After running the program, all diameters were chosen based on typically available pipe diameter, as seen in the diameter column. SewerGEMS can also be used to verify variables linked to manholes (Appendix D). The ground level and the depth of the manholes, or invert altitude, are two important criteria to consider in manholes. 


\section{CONCLUSION}

This study aimed to see whether decentralized wastewater collection schemes or regional networks were feasible. Consequently, the 5th district of Kabul city has been chosen as a research location, and two out of nine divided zones within it were investigated. The research area's LULC and topographic map were modified and generated in the Arc GIS setting using Satellite Photo and DEM. Different shapefiles for pipelines and manholes were created in the Arc map framework to develop the architectural model. The developed architectural model is imported to SewerGEMS software and adapted for a hydrological model.

SewerGEMS software was used to perform the model's hydraulic assessment. The geometric modeling and hydraulic analysis results show that decentralized and regional wastewater collection systems are viable options for Kabul city and look appropriate options. Nevertheless, after developing many simulations of various scenarios, the hydraulic model design at the 5th district level for two research zones by the SewerGEMS program was eventually completed based on maximum discharge. It can be inferred that the hydraulic model was successfully developed and operated after analyzing the hydraulic analysis findings and evaluating control parameters like flow rate, the diameters of pipelines, slopes, pipeline's profiles, and so on. Such models can be applied to city sizes at the district level. A large portion of Kabul city was built without a master plan. The lack of a consistent urban plan makes it difficult to create such models; this analysis aims to include additional tools in the gravity system for both planned and unplanned regions. The utilization of "wet wells" and "lift stations" will primarily overcome the system's dilemma.

\section{REFERENCES}

Afzali, A. O. (2017). Physicochemical and Bacteriological Quality of groundwater in Kabul basin, Afghanistan. IOSR Journal of Agriculture and Veterinary Science, 10(03), 58-61. https://doi.org/10.9790/2380-1003025861

Akshaya, N., \& Jesse, D. (2020). Using ModelBuilder to Import External Data. Bentely Comunities.https:// communities.bentley.com/products/hydraulics hydrology/w/hydraulics_and_hydrology_wiki/2821/usingmodelbuilder-to-import-external-data

Aleisa, E., \& Alshayji, K. (2019). Analysis on reclamation and reuse of wastewater in Kuwait. Journal of Engineering Research, 7(1), 1-13.

Ali, H. (2017). BBC. https://www.bbc.com/persian/afghanistan-40787693

Bhave, P., \& Rahate, S. (2018). Impact of Redevelopment Projects on Waste Water Infrastructure. Journal of The Institution of Engineers (India): Series A, 99(3), 503-509. https://doi.org/10.1007/s40030-018-0303-x

Brati, M. Q., Ishihara, M. I., \& Higashi, O. (2019). Groundwater level reduction and pollution in relation to household water management in Kabul, Afghanistan. Sustainable Water Resources Management, 5(3), 13151325. https://doi.org/10.1007/s40899-019-00312-7

Bu Qammaz, A., AlHamed, S., AlNasser, F., \& Alkhalidi, M. (2020). Integrated Coastal Zone Management in Kuwait: A Knowledge-Based System Model. Journal of Engineering Research, 8(4), 29-44. https://doi. org/10.36909/jer.v8i4.7931

Chawla, A., \& Singh, S. K. (2014). Modelling of Contaminant Transport from Landfills. International Journal of Engineering Science and Innovative Technology, 3(5), 222-227.

CIA. (2020). The World Fact Book. https:/www.cia.gov/library/publications/the-world-factbook/geos/af.html

Consortium for DEWATS Dissemination Society. (2017). Technical assessment of faecal sludge management in Kabul (Issue November). 
Dan, I., \& Jesse, D. (2020a). How do each of the LoadBuilder methods work? Bentely Comunities.https:// communities.bentley.com/products/hydraulics hydrology/w/hydraulics_and_hydrology_wiki/10862/howdo-each-of-the-loadbuilder-methods-work

Dan, I., \& Jesse, D. (2020b). Using Terrain Extractor (Trex). Bentely Comunities. https://communities.bentley.com/ products/hydraulics hydrology/w/hydraulics_and_hydrology wiki/8281/using-terrain-extractor-trex

Frahmand, A. S. (2011). GIS based Ground Water Quality Analysis in Kabul City Region. Geospatial World Forum, 1-13. https://www.researchgate.net/publication/284352960 GIS_based_Ground_Water_Quality_Analysis_in_ Kabul_City_Region

Gesim, N. A., \& Okazaki, T. (2018). Groundwater Quality Mapping Using Water Quality Index in the Kabul City , Afghanistan. August, 29-34.

Hayat, E., \& Baba, A. (2017). Quality of groundwater resources in Afghanistan. Environmental Monitoring and Assessment, 189(7). https://doi.org/10.1007/s10661-017-6032-1

Houben, G., \& Tünnermeier, T. (2005). Hydrogeology of the Kabul Basin Part II : Groundwater geochemistry and microbiology. BGR.

Kanakiya, R. S., Singh, S. K., \& Shah, U. (2015). GIS Application for Spatial and Temporal Analysis of the Air Pollutants in Urban Area. International Journal of Advanced Remote Sensing and GIS, 4(1), 1120-1129. https:// doi.org/10.23953/cloud.ijarsg.102

Kumar, A., Mishra, R. K., \& Singh, S. K. (2015). GIS Application in Urban Traffic Air Pollution Exposure Study: A Research Review. Suan Sunandha Science and Technology Journal, 2(1January), 25-37.

Noori, K. M. A., \& Nasimi, M. N. (2019). Kabul City Groundwater and Need for Artificial Recharge. Proceedings of the 4th International Conference on Civil, Structural and Transportation Engineering (ICCSTE'19), 1-7. https:// doi.org/10.11159/iccste19.215

NSIA. (2020). Estimation-Population-Final-Year 2020.

Paiman, Z., \& Noori, A. R. (2019). Evaluation of Wastewater Collection and Disposal in Kabul City and Its Environmental Impacts. Modern Environmental Science and Engineering, 5(5), 451-458. https://doi. org/10.15341/mese(2333-2581)/05.05.2019/012

Rhimi, O., \& Murakmi, K. (2017). Rooftop rainwater harvesting and its efficiency in Kabul new city. 土木学 会 論 文集 G （環 境 ），73(5)，25-30. https://www.jstage.jst.go.jp/ article/jscejer/73/5/73_I_25/_pdf/-char/ja

Seddeqi, M. Q. (2017). Water Supply Engineering (2nd ed.). Nawesa.

Shafaqna. (2019). shafaqna. Shafaqna News Webpage. https://af.shafaqna.com/FA/341927

Zaryab, A., Noori, A. R., Wegerich, K., \& Kløve, B. (2017). Assessment of water quality and quantity trends in Kabul aquifers with an outline for future drinking water supplies. Central Asian Journal of Water Research, 3(2), 3-11. http://www.water-ca.org/article/1925

Zhang, D., Martinez, N., Lindholm, G., \& Ratnaweera, H. (2018). Manage Sewer In-Line Storage Control Using Hydraulic Model and Recurrent Neural Network. Water Resources Management, 32(6), 2079-2098. https://doi. org/10.1007/s11269-018-1919-3 